\title{
Factors Influencing Staff Motivation among Employees: A Case Study of Equator Bottlers (Coca Cola) Kenya
}

\author{
Mary Elector Odukah \\ Stamford University, Krung Thep Mahanakorn, Thailand \\ Email: moelecky430@gmail.com
}

Received 9 March 2016; accepted 4 June 2016; published 7 June 2016

Copyright (C) 2016 by author and Scientific Research Publishing Inc.

This work is licensed under the Creative Commons Attribution International License (CC BY). http://creativecommons.org/licenses/by/4.0/

(c) (i) Open Access

\begin{abstract}
This study sought to analyze: (1) the effect of employee recognition on motivation; (2) the relationship between working conditions and motivation of staff; and (3) the contribution of personal development to motivation of staff. A sample of 278 employees out of 1000 employees was selected for study. Survey questionnaires were used to collect data. The findings showed that employee motivation at Equator bottlers was influenced by employees' performance recognition, working conditions, training and development. As a result, the study recommended that since employee motivation remained an understudied issue among Kenyan companies; further studies should be conducted with respondents sampled from different industries in order to further understanding particularly how motivation strategies resonated with various organizational cultures in the Kenyan context. Further studies should also include quasi experimental studies in order to advance theoretical understanding of the effect of motivational strategies on employees in Kenya's organizational cultures.
\end{abstract}

\section{Keywords}

Staff Motivation, Coca Cola, Kenya

\section{Introduction}

Most studies that have been conducted on motivation have taken motivation as an independent variable with organization performance as the dependent variable. In other words, most studies have explored the effect that motivation of employees has on the performance of employees or the organization. Most of these studies establish that there is a positive relationship between employee motivation and performance. For example, Ayobami 
studies two types of motivation namely intrinsic and extrinsic motivation and how they affect performance of employees. Intrinsic motivation factors such as successful completion of tasks, job enrichment are related to the work itself [1]. Extrinsic factors are factors outside the job such as remuneration and rewards. Asim explores motivation as indicated by rewards and its effects on performance of employees. He establishes that with everything else held constant, increased rewards cause an improvement on performance of employees [2].

Though the influence of motivation on performance is clear, the factors influencing motivation are what need to be studied. By knowing the factors affecting motivation organization will know what to control so as to have improved motivation which previous studies have shown an effect on performance. The studies above do not establish the factors affecting motivation but explore how motivation affects performance of employees. This is the gap that this study will seek to fill by studying the factors influencing employee motivation with a focus on the Equator Bottlers in Kisumu, Kenya. The study would be done in Equator Bottlers because in 2014, Equator Bottlers went through a staff restructuring process with an aim of improving the profitability of the company [3]. Restructuring has a potential to lead to de-motivation of staff if not well managed [4]. This is also one of the objectives that the study will seek to establish. A review of literature also reveals that no study has been conducted to analyze the factors affecting staff motivation at the equator bottlers. This is a gap that this study will seek to fill. Therefore, the purpose of this study is to: (1) analyze the effect of employee performance recognition on motivation; (2) analyze the relationship between working conditions and motivation of staff; and (3) analyze the contribution of personal development to motivation of staff.

\section{Literature Review}

\subsection{Factors Affecting Job Motivation}

Primarily studies on job motivation are concerned with the factors that influence people to behave in certain ways. The question is to establish the force that drives employees to work has been the essential goal of making job a satisfying venture. Theories differ on what factors comprise job motivation. From past studies, there has been interesting claims and counterclaims about job motivation trend in organization over the years because various factors have been found as having direct relationship with employee job motivation. However the overreaching suggestion is composed of both work motivation and environmental motivation [5].

In particular, Gupta classifies factors influencing job motivation into two major categories. These are environmental and personal factors [6]. In his studies on job motivation of accountants and engineers, Herzberg (1966) found that the factors involved in producing job motivation (or motivation) are distinct and different from factors that lead to job demotivation and the factor that producing job motivation (or motivation) are concerned primarily with the actual job content (or work process factor).The reason for demotivation (or work process factors) deal with primarily factors relating to the context in which the job is done, that is the job environment. Both sets of factors are closely interrelated and can make people unhappy if they are poorly managed. Herzberg believes that no matter how good these factors are made good, they will make people truly satisfied or motivated to do a good job [7]. Despite widespread criticism from a cross section of scholars, Herzberg's two models remain popular today.

Studies of nurses' job motivation shows that service quality and nurse retention chain are main sources of motivation [8]. In addition, the writers identified two main sources of job demotivation as staff shortages and poor management. Savery in the studies of job factors (under direct control of management) on employee job motivation in a major local government headquarters in Australia found conflict whether internal or external as significant factors leading to reduced job motivation. Savery, recommends a management by objective schemes as a strategy to overcome the problem identified [9].

A study on South African doctors' job motivation revealed that overall; doctors were dissatisfied with their work [10]. Among the variables measured, the study cited that doctors are highly dissatisfied with practice pressures and work setting. Lack of challenge and self-direction is the most common job complaint among the members of educated work force in America [11]. Further findings indicated that among the unmotivated staff, $36 \%$ of American workers felt underutilized, 32\% believed they are "overeducated" for their jobs, and more than $50 \%$ complained about a lack of control over the days they work and their job assignment. Overspecialized work that is deficient in challenge was a prime cause of lower job motivation and relationship between personality and job motivation. The study also found an inverse relationship between job motivation and turnover intentions. Studies on the effects of needs (based on Maslow's hierarchy of needs) and organizational factors of kin- 
dergarten teachers found teachers being most satisfied on the two lower needs (security and social) and least satisfied on higher needs (esteem, autonomy, and self-actualization) [12]. Abraham and Wright presented survey evidence that protection against job loss grows with employees' length of service even after controlling the perceived net value of employees to the firm. While longer service generally translates into addition protection, no evidence supports protection as directly increasing the job motivation level of workers. However, the researcher made further argues that protection against unfair dismissal positively is directly related to job motivation [11].

\subsection{The Effect of Employee Performance Recognition on Motivation of Staff}

Generally, employees want their achievement recognized and rewarded. This is against the backdrop of understanding that, recognition of good performance as an important aspect that raises job motivation and raises employee morale. Employees would always strive to do a good job as long as they are placed in positions that use their talents and where goals are not only clearly defined but achievable [13]. In this case the managers are required to provide necessary guidance, direction, and support on goal path and standards of performance. Defining standards of performance and timely feedback on performance is an effective way of providing adequate job challenge to individual workers on their jobs. Unclear targets blurred objectives and poor communication can contribute to low motivation and eventually lead to poor work performance.

A study on job intrinsic factor imparting on job motivation of casino hotel chefs found that the chefs are most motivated with work itself and least satisfied with growth and recognition they were accorded. The study recommended need for increased recognition at work and creation of special incentive programs tailored to specific kitchen types [14]. Similarly, nurses shows that their level of job motivation was most influenced when a manager gave recognition, praises, and thanks [15]. Concise studies on workers in a manufacturing company, shows job motivation as a strategy leading to significant reduction of absenteeism [16]. The writers established rate of absenteeism immediately reducing by $18 \%$ and remained low as long as incentives are offered.

Organizational inability to induce job motivation is one of the paramount indicators of deteriorating conditions in working places [13]. On the other hand, a study on job intrinsic and extrinsic factors imparting on job motivation of Casino hotel chefs reveals that, on the extrinsic factors, chefs were most satisfied with supervision and least satisfied with company polices [17].

Organizational policies and laws that promote employee dignity, positive attitude, and morale could push job motivation, which changes perceptions about work. That way, employees are enabled to enjoy their responsibilities, on tasks that they do, and perform well in their assignments. Good organizational policies should be clear and describe in detail what is expected of employees and the situations under which each of the action taken would apply. This study shows that the discretional behavior exhibited by the organization towards goal achievement may be limited if staff are motivated or in other words, staff motivation and goal achievement and motivation of staff was directly related.

\subsection{Working Conditions and Motivation of Staff}

Studies show that the environment in which people work has a tremendous effect on their level of pride both for them and for the work they are doing. Naturally, employees prefer working conditions that they view as safe and to develop more sense of motivation from their work. [18] found that overall doctors were dissatisfied with their work. Among the variables measured, the study cited that doctors are highly dissatisfied with practice environmental pressures and work setting. The study suggest that opportunities for enhancing doctors job motivation exist so long as management works in collaboration with doctors to provide the specific working conditions that health professional desire. Additionally, most employees prefer working relatively close to home, in clean and relatively modern facilities and with appropriate tools and equipment. Employees tend to prefer a job that gives them opportunities to use their skills and abilities and offer a variety of tasks, freedom, and feedback on how well they performed. Because of differential levels in degrees of motivation and individual needs fulfillment, employees perceive some jobs as dull, repetitive, or boring and yet others are seen as satisfying, rewarding and carry high status with them [19].

Employee values and job expectations significantly moderate job motivation [20]. Job content for example is a critical determinant of whether employees believe that good performance on the job leads to feelings of accomplishment, growth, and self-esteem; this occurs when jobs are intrinsically motivating. A survey on job motivation and utilization of skills of enlisted white men in the continental US Army in 1943 revealed that proper 
job assignment as an important factor to morale and efficiency. The study also revealed that men like their Army jobs, if they get the job they asked for. Men who are given no choice of jobs and those who asked for a job but fail to get are usually much less satisfied. The study further revealed that the infantry had the smallest number of men serving in jobs they chose and highest number of men with low job motivation.

The contribution of training and personal development on motivation of staff.

Training is the process that enable people to acquire new knowledge learn new skills and perform tasks differently and better than before [20]. The definition is quite relevant to the present study because trained employees perform duties confidently [21]. Training is the imparting of proficiencies and knowledge that are specifically related to a relatively narrow area of employment, whereas development implies individual growth and self-realization a broad area [20].

Training then helps people to adapt to a role behavior that will be useful to the organization. Traditionally, training was the responsibility of schools but this has changes and now organizations have become in providing both specific job training and general training. Lack of training and induction on the job and limited access to career development are some of the main factors influencing motivation and job motivation of the staffing department at the Teachers Service commission. Lack of well-organized training program may think they are not progressing rapidly enough and that advancement is slow which culminates into low job motivation [21].

Other researches provide evidence that training has a positive effect on motivation of staff and organizational performance [22]. This relationship eventually leads to improvement in organizational performance. There is a direct relationship between training and organization and motivation with a correlation coefficient of 0.233 and a correlation of 0.297 between motivation and employee performance. We see here, for a firm to achieve higher performance it needs to have improved motivation of employees which is dependent on training of staff. We can be able to infer from these findings that it is not possible for an organization to achieve higher performance without motivated staff. Training can be used as an approach of knowledge needs of employees and then fill the gaps in competency gaps needed for them to perform better and achieve their individual goals and ultimately their organizational goals [23]. A study on the effect of training on performance of staff in the telecommunication sector shows a coefficient of determination of 0.501 for the performance and employee training which implied that that $50.1 \%$ of variation in employee performance could be explained by employee training [21]. Further, he conducted a t test to establish the effect of training on motivation of employees by grouping employees who were trained and those who were not trained and comparing their motivation. It yielded a T-value was 8.58 that meant that training had a significant effect on motivation. Staff development through training has an impact on staff motivation through their achievement of their job goals [12]. With staff that are knowledgeable through trainings they are able to achieve their personal goals which leads to staff being motivated.

Training is an approach of reducing the knowledge gap through interventions of training son particular skills and abilities [16]. Additionally, he points out that trainings should facilitate an organization to know what staff is not performing well and what needs to be improved. In this case, improved employee performance may occur because of a quality training program that leads to employee motivation and jobs needs fulfillment. These findings support the view that employee competencies improve through training [20].

\subsection{Theoretical Framework}

Maslow Hierarchy of Needs Motivational Theory: Maslow Hierarchy of Needs Motivational Theory is used to understand human motivation, management training, and personal development [21]. It is intended to help employers to assist employees to realize self-actualization, a point at which it is assumed that such employees will be motivated to give their best contribution to the company. This theory assumes that to realize self-actualization among employees; each category of needs should be addressed one at a time namely: biological and psychological needs (food, water, shelter etc.); safety needs (security, stability etc.); belongingness and love needs (affection; relationships, etc.); esteem needs (achievement; status; responsibility, reputation etc.); and self-actualization (personal growth and fulfillment). The major limitation of Maslow's theory is that Maslow did not consider environmental factors which have in the long run shown to affect employee satisfaction and motivation. As a result, there is need to consider another theory to supplement environmental factors.

Frederick Herzberg Motivational Theory: This is a management and motivation theory which assumes that to enrich work, employees ought to be motivated. It assumes that satisfaction or dissatisfaction of employees at work place may result from a range of factors namely: achievement; recognition; work itself; responsibility; ad- 
vancement; personal growth; supervision; relationship with supervisor; company policy and management practices; work conditions; salary; relationship with peers; personal life; status; and security [13]. The implication of this theory is that to be able to motivate employees at work place; solutions should be tailored to address sociopsychological needs of the employees enlisted above.

\subsection{Conceptual Framework}

This conceptual framework is crafted from the empirical literature in this study and by integrating elements of Maslow Hierarchy of Needs Motivational Theory and Frederick Herzberg Motivational Theory in order to formulate concepts that incorporate main socio-psychological issues that account for employee motivation at work place, particularly from the perspective of what a firm ought to look at or address in order to improve employee satisfaction which then leads to employee motivation. The integration of these theoretical concepts is also based on the idea that needs as a component of employee satisfaction and motivation can be both personal and environmental. It can be personal in the sense that an organization can prioritize which employee needs to meet first depending on the particular set of employees. It can also be environmental because employees are exposed to different environmental factors which influence employees' psycho-social well-being through lived experiences.

The conceptual framework that will guide the study will is as presented in Figure 1. The intent is to establish that with increased employee performance recognition, working conditions, training and personal development, alignment of staff with the job demands from the restructuring process and supervisors' interpersonal relationship; there will be increased employee motivation which in turn will lead to improved employee job motivation. On the other hand, with reduced employee performance recognition, working conditions, training and personal development, job security and supervisors interpersonal relationship, there will be reduced employee motivation which may in turn lead to reduced employee motivation.

\subsection{Research Hypothesis}

The study tested the following null hypotheses.

1. Employee recognition has no relationship to motivation of staff.

2. There is no relationship between working conditions and motivation of staff.

3. Training and personal development has no relationship to motivation of staff.

\section{Methodology}

This study adopted descriptive survey research design. Descriptive survey design is good for collective large amounts of data using questionnaires. The method is extensive and cost effective [23]. It also gives the study an opportunity to get accurate view of response to issues as well as test hypothesis on social relationship at both the individual and group level, maintains a high level of confidentiality, is convenient and enables data to be collected faster [6]. A sample of 278 employees out of 1000 employees was selected for study. Closed and open ended survey questionnaires were used to collect data. The items on the survey questionnaire covered the following topics: demographic information of the respondents (gender, age, occupation, and years respondents had worked in the organization); the effect of employee performance recognition on motivation of staff; the relationship of working conditions and motivation of staff; the contribution of training and personal development on motivation of staff). To pre-test the instrument, the researcher conducted a pilot study in which the respondents were MBA students. The instrument was further revised before it was finally sent to the respondents for data collection.

Independent variables Dependent variable

Employee performance recognition Motivation of staff

Working conditions Moderating variable

Tra ining and personal development Employee satisfaction

Source: Researcher, 2016

Figure 1. Conceptual framework. 
The following ethical considerations guided the study: (1) Members of the staff who were involved in the study were those that were requested and were willing to participate in the study. (2) They participated in the study at their own convenience. (3) The researcher also ensured privacy, informed consent, confidentiality, and anonymity of the respondents. (4) The draft of the study was shared with participants in order to obtain further input or verify if the interview data reflected as accurate as possible the heads of department's contribution. The data was analyzed according to the objectives of the study. The data was mainly quantitative and was analyzed using descriptive and inferential statistics.

\section{Results of the Study}

\subsection{Personal Data of Respondents}

This section presents the personal information of the respondents who were involved in the study. The study sought to target 278 employees and 6 heads of departments but managed to get the views of 263 employees and 6 heads of departments; translating to a study response rate of $94.6 \%$ employees and $100 \%$ heads of departments. Out of the 263 employees who responded to the study, 136 (51.71\%) were male and the other 127 (48.29\%) were female. This shows that there was an equal representation of male and female respondents reducing bias of results due to gender.

Years of experience can be used as an indicator of the period taken in an organization to observe the operation of an organization and to competently report about them. The study also shows that 29 (11.03\%) employees had been in the organization for less than 2 years, 97 (36.88\%) employees had been working in Equator bottlers for a period ranging between 2 and 5 years, 104 (39.54\%) employees had been in the organization for between 5 and 10 years and 33 (12.55\%) had stayed in the organization for more than 10 years. From these findings, it is clear that most respondents had been in the organization for a long time to adequately respond about factors that influence their motivation at work. Most of the employees were over 35 years of age. A total of 137 (52.09\%) employees said that they were found to be over 35 years of age. Very few employees $(9.13 \%)$ were below 25 years.

\subsection{The Effect of Employee Performance Recognition on Motivation}

The first objective of the study was to analyze the effect of employee recognition on motivation of staff at the equator bottlers. The study first sought to know from the employees in the past 12 months, whether the management has ever recognized something that they had done for the organization. The results of the study show that most employees had their performance recognized by the organization over the past 12 months. It is still worth noting that $43.35 \%$ of the employees had not been recognized by the organization. The study sought to know from the employees who had been recognized the strategies that were used by the organization to recognize their performance. Table 1 shows the recognition strategies used by the organization.

Table 1 shows that employees were of the view that the most commonly used method of acknowledging staff was public acknowledgement of performance of staff during meetings. $20.91 \%$ of employees said that this was

Table 1. Recognition strategies used by the organization.

\begin{tabular}{|c|c|c|}
\hline Strategies & Frequency & Percentage \\
\hline 1. Publicly acknowledging good work during meetings & 55 & 20.91 \\
\hline 2. Remunerations increments to good performing staff at work & 48 & 18.25 \\
\hline 3. Getting awards for good work for example employee of the month awards & 42 & 15.97 \\
\hline 4. Job evaluation on targets achieved & & 11.79 \\
\hline 5. Getting gestures of appreciation from the director & & 10.65 \\
\hline 6. Staff annual appraisal & 27 & 31 \\
\hline 7. Getting challenging work delegated to me by the seniors & 19 & 28 \\
\hline 8. Promotions of good performing staff & 11 & 4.18 \\
\hline 9. I don't know & 2 & 0.76 \\
\hline
\end{tabular}


the main approach for recognizing employee performance.

The study also sought to know from the staff the extent to which they felt their work is valued and appreciated. Table 2 shows the results of the findings. Table 2 shows that a proportion of $54.34 \%$ of employees either felt valued and appreciated to a high or very high extent. Still however, a sizable proportion of staff was feeling their work is valued or appreciated to a low or very low extent.

The study explored the extent to which the employees felt a sense of ownership and belonging to the work they did and presented the findings in Table 3. Most employees felt a sense of ownership and belonging to their work. A proportion of $58.93 \%$ of employees said that they felt a sense of belonging and ownership to their work to a high extent.

Table 4 shows the analysis of the null hypothesis that there is no relationship between recognition and motivation of staff. The correlation analysis between performance recognition and motivation was found to be 0.2082 with a $P$ value of 0.0007 . The $P$ value was less than 0.05 , meaning that we reject the null hypothesis and conclude that there was a significant positive association between performance recognition and motivation of staff.

\subsection{The Relationship between Working Conditions and Motivation of Staff}

The second objective was to analyze the relationship between working conditions and motivation of staff at the equator bottlers. The study analyzed several aspects of working conditions such as work home balance, flexibility of working times, compensation and rewards, protection in case of disciplinary and infrastructure support in the organization. The study used cross tabulations to assess the relationship between these aspects and motivation. Table 5 shows the association between work home balance and motivation of staff.

It came out that $50.57 \%$ of staff rated the work home balance as either very poor or poor. For the 49 employees who rated their work home balance as very good, 34 (69.39\%) felt motivated to go an extra mile at work. This shows that improved work home balance was associated with motivation at work.

Table 2. Staff opinion on how their work is valued and appreciated.

\begin{tabular}{|c|c|c|}
\hline To what extent do you feel your work is valued and appreciated? & Frequency & Percentage \\
\hline Very low extent & 39 & 14.83 \\
\hline Low extent & 81 & 30.8 \\
\hline High extent & 97 & 36.88 \\
\hline Very high extent & 46 & 17.49 \\
\hline Total & 263 & 100 \\
\hline
\end{tabular}

Table 3. Staff opinion on sense of ownership and belonging to their work.

\begin{tabular}{lcc}
\hline To what extent do you feel a sense of ownership and belonging & Frequency & 38 \\
\hline Very low extent & 70 & 14.45 \\
Low extent & 108 & 26.62 \\
High extent & 47 & 41.06 \\
Very high extent & $\mathbf{2 6 3}$ & 17.87 \\
Total & $\mathbf{1 0 0}$ \\
\hline
\end{tabular}

Table 4. Correlation between recognition and motivation.

\begin{tabular}{cc}
\hline Correlation between performance recognition and motivation of staff & Correlation coefficient \\
\hline $\mathrm{N}=263.0007$ & 0.2082 \\
\hline
\end{tabular}
$\mathrm{N}=263$. 
Table 5. Association between work home balance and motivation.

\begin{tabular}{|c|c|c|c|c|c|c|c|c|c|c|}
\hline \multirow{3}{*}{$\begin{array}{l}\text { How would you } \\
\text { rate your work } \\
\text { home balance }\end{array}$} & \multicolumn{8}{|c|}{ To what extent do you feel motivated to go an extra mile in your work to get good performance } & \multicolumn{2}{|c|}{ Total } \\
\hline & \multicolumn{2}{|c|}{ Very low extent } & \multicolumn{2}{|c|}{ Low extent } & \multicolumn{2}{|c|}{ High extent } & \multicolumn{2}{|c|}{ Very high extent } & \multirow[b]{2}{*}{ Freq. } & \multirow[b]{2}{*}{$\%$} \\
\hline & Freq. & $\%$ & Freq. & $\%$ & Freq. & $\%$ & Freq. & $\%$ & & \\
\hline Very poor & 20 & 31.25 & 14 & 21.88 & 23 & 35.94 & 7 & 10.94 & 64 & 100 \\
\hline Poor & 17 & 24.64 & 19 & 27.54 & 26 & 37.68 & 7 & 10.14 & 69 & 100 \\
\hline Good & 5 & 6.17 & 27 & 33.33 & 36 & 44.44 & 13 & 16.05 & 81 & 100 \\
\hline Very good & 7 & 14.29 & 8 & 16.33 & 13 & 26.53 & 21 & 42.86 & 49 & 100 \\
\hline Total & 49 & 18.63 & 68 & 25.86 & 98 & 37.26 & 48 & 18.25 & 263 & 100 \\
\hline
\end{tabular}

Pearson chi square variate $(9)=41.4902 ; \mathrm{P}$ value $=0.000$

Secondly the study assessed the relationship between flexibility of working times in terms of adjustments of times of arrival or leaving of work and motivation and presented the findings in Table 6.

Table 6 shows that most of the employees who rated the flexibility of their working times as very good also reported that they were motivated to a high or very high extent. On the other hand, most of the employees who rated the flexibility of their working times as very poor reported that they were motivated to a low or very low extent. Table 7 shows correlation analysis of the hypothesis: There is no relationship between working conditions and motivation of staff.

The correlation analysis between working conditions and motivation was found to be 0.3427 with a P value of 0.0000 . The $\mathrm{P}$ value was less than 0.05 , meaning that we reject the null hypothesis and conclude that there was a significant positive association between working conditions and motivation of staff.

\subsection{The Contribution of Personal Development to Motivation of Staff}

The third objective of the study was to analyze the contribution of training and personal development on motivation of staff. It was established that the proportion of employees who had been trained and not trained in the organization were more or less the same. A total of 133 (50.57\%) employees said they had never been trained. The study also analyzed the effect of job training and motivation of staff and presented the findings in the cross tabulation in Table 8.

It was shows that that given the low level of the company investment in training, it was difficult to conclude to a considerable extent whether training of employees in the organization and motivation were not associated. However, the following findings offer insights into the contribution of training to employee motivation.

The study also found that most employees had been trained twice. Out of the 130 employees who had ever been trained at equator bottlers, 79 (60.77\%) of them had been trained twice and 44 (33.85\%) had been trained thrice. The findings of the study also show that most employees found the trainings to be beneficial with 52 (40\%) employees rated the 43 (33.08\%) employees rated the trainings as relevant. Only $29.93 \%$ felt the trainings were not relevant. An investigation into the association between academic qualifications and motivation is presented in a cross tabulation analysis labeled in Table 9.

Table 9 shows that most of the employees who were of the view that academic qualifications had a bearing on how they were rewarded were motivated to a high or very high extent. Specifically $71.01 \%$ of employees who said that academic qualifications had a bearing on how they were rewarded were motivated to a high or very high extent. On the other hand $61.6 \%$ of employees who said that academic qualifications had no bearing on how they were rewarded were motivated to a low or very low extent.

The third hypothesis null hypothesis that was tested was that there is no relationship between training and personal development and motivation of staff. The correlation analysis results are presented in Table 10.

The correlation analysis between training and personal development and motivation was found to be 0.3427 with a $\mathrm{P}$ value of 0.0000 . The $\mathrm{P}$ value was less than 0.05 , meaning that we reject the null hypothesis and conclude that there was a significant positive association between training and personal development and motivation of staff. 
Table 6. Influence of flexibility on motivation.

\begin{tabular}{|c|c|c|c|c|c|c|c|c|c|c|}
\hline \multirow{3}{*}{$\begin{array}{l}\text { How would you rate } \\
\text { the flexibility of your } \\
\text { working times? }\end{array}$} & \multicolumn{8}{|c|}{ To what extent do you feel motivated to go an extra mile in your work to get good performance } & \multicolumn{2}{|c|}{ Total } \\
\hline & \multicolumn{2}{|c|}{ Very low extent } & \multicolumn{2}{|c|}{ Low extent } & \multicolumn{2}{|c|}{ High extent } & \multicolumn{2}{|c|}{ Very high extent } & \multirow[b]{2}{*}{ Freq. } & \multirow[b]{2}{*}{$\%$} \\
\hline & Freq. & $\%$ & Freq. & $\%$ & Freq. & $\%$ & Freq. & $\%$ & & \\
\hline Very poor & 21 & 38.18 & 11 & 20 & 16 & 29.09 & 7 & 12.73 & 55 & 100 \\
\hline Poor & 11 & 14.86 & 26 & 35.14 & 33 & 44.59 & 4 & 5.41 & 74 & 100 \\
\hline Good & 13 & 15.48 & 21 & 25 & 28 & 33.33 & 22 & 26.19 & 84 & 100 \\
\hline Very good & 4 & 8 & 10 & 20 & 21 & 42 & 15 & 30 & 50 & 100 \\
\hline Total & 49 & 18.63 & 68 & 25.86 & 98 & 37.26 & 48 & 18.25 & 263 & 100 \\
\hline
\end{tabular}

Pearson chi square variate $(9)=36.2048 ; \operatorname{Pr}=0.000$.

Table 7. Correlation between working conditions and motivation.

\begin{tabular}{ccc}
\hline & Correlation coefficient & P value \\
\hline Correlation between working conditions and motivation of staff & 0.3427 & 0.0000 \\
\hline
\end{tabular}

Table 8. Association between training and motivation.

\begin{tabular}{|c|c|c|c|c|c|c|c|c|c|c|}
\hline \multirow{3}{*}{$\begin{array}{l}\text { Have you ever been } \\
\text { offered job training by } \\
\text { the organisation? }\end{array}$} & \multicolumn{8}{|c|}{ To what extent do you feel motivated to go an extra mile in your work to get good performance } & \multicolumn{2}{|c|}{ Total } \\
\hline & \multicolumn{2}{|c|}{ Very low extent } & \multicolumn{2}{|c|}{ Low extent } & \multicolumn{2}{|c|}{ High extent } & \multicolumn{2}{|c|}{ Very high extent } & \multirow[b]{2}{*}{ Freq. } & \multirow[b]{2}{*}{$\%$} \\
\hline & Freq. & $\%$ & Freq. & $\%$ & Freq. & $\%$ & Freq. & $\%$ & & \\
\hline Yes & 24 & 18.46 & 34 & 26.15 & 44 & 33.85 & 28 & 21.54 & 130 & 100 \\
\hline No & 25 & 18.8 & 34 & 25.56 & 54 & 40.6 & 20 & 15.04 & 133 & 100 \\
\hline Total & 49 & 18.63 & 68 & 25.86 & 98 & 37.26 & 48 & 18.25 & 263 & 100 \\
\hline
\end{tabular}

Pearson chi square variate $(3)=2.3402$; $\mathrm{P}$ value $=0.505$.

Table 9. Association between academic qualifications and performance.

\begin{tabular}{|c|c|c|c|c|c|c|c|c|c|c|}
\hline \multirow{3}{*}{$\begin{array}{l}\text { Does you academic } \\
\text { qualifications have a } \\
\text { bearing on how you } \\
\text { are rewarded? }\end{array}$} & \multicolumn{8}{|c|}{ To what extent do you feel motivated to go an extra mile in your work to get good performance } & \multicolumn{2}{|c|}{ Total } \\
\hline & \multicolumn{2}{|c|}{ Very low extent } & \multicolumn{2}{|c|}{ Low extent } & \multicolumn{2}{|c|}{ High extent } & \multicolumn{2}{|c|}{ Very high extent } & \multirow[b]{2}{*}{ Freq. } & \multirow[b]{2}{*}{$\%$} \\
\hline & Freq. & $\%$ & Freq. & $\%$ & Freq. & $\%$ & Freq. & $\%$ & & \\
\hline Yes & 20 & 14.49 & 20 & 14.49 & 61 & 44.2 & 37 & 26.81 & 138 & 100 \\
\hline No & 29 & 23.2 & 48 & 38.4 & 37 & 29.6 & 11 & 8.8 & 125 & 100 \\
\hline Total & 49 & 18.63 & 68 & 25.86 & 98 & 37.26 & 48 & 18.25 & 263 & 100 \\
\hline
\end{tabular}

Pearson chi square variate $(3)=32.5804 ; \mathrm{P}$ value $=0.000$.

Table 10. Correlation between training, personal development and motivation.

\begin{tabular}{ccc}
\hline & Correlation coefficient \\
\hline Correlation between training and development with motivation of staff & 0.2376 \\
\hline
\end{tabular}

\section{Summary and Discussion}

The main purpose of the study was to establish the factors influencing staff motivation at Equator bottlers. The study had three hypotheses: (1) there was no relationship between recognition and motivation of staff; (2) there 
was no relationship between working conditions and motivation of staff; and (3) there was no relationship between training and personal development and motivation of staff. A number of factors were discovered to have significant association to motivation of staff at Equator bottlers. These were employee's performance recognition, working conditions, training and personal development. These factors, at $5 \%$ level of significance had an influence on motivation of employees.

As indicated earlier in literature review, both environmental and personal factors account for staff motivation. These two factors tend to cut across theories on motivation [5]. In light of this understanding, job motivation can be basically classified into two categories namely: environmental and personal factors [6].

Previous studies indicate that employees want their achievement recognized and rewarded. Based on this view, recognizing the efforts and achievements employees make at work place is believed to play a role in employee motivation. The following studies for example suggest that: (1) putting employees in positions where they can utilize their talents and where they can achieve results with their skills influences job motivation [13]; (2) giving grants and bonuses to employees will motivate them because such practices indicate recognition [6]; (3) creation of tailored incentives to recognize and motivate a range of employees working in different departments and hence having varied response to different incentives for motivation [14]; and changing organizational structures that have negative implications on employees' wellbeing for example conditions that increase anxiety, work-life and family conflict, and workers perceived loss of control [20].

The findings of this study indicated that $54.34 \%$ of employees either felt valued and appreciated to a high or very high extent compared to that $43.35 \%$ of the employees who had not been recognized by the organization. Furthermore, 58.93\% of employees said that they felt a sense of belonging and ownership to their work to a high extent. Public acknowledgement was reported to be the most dominant way the company used to recognize its employees (20.91\%). Concerning the association between feeling appreciated and motivation to work, $60.87 \%$ of employees who reported that their work had been recognized also reported that they were motivated. On the other hand, 53.6\% of employees who reported that their work had not been recognized and also reported low motivation to work. The study also showed that while majority of the employees surveyed reported that their work had been recognized and that they were motivated; the difference between those who reported that their work had been recognized and those who reported that their work had not been recognized was little. This implied that the organization should invest more in recognizing employees so that it could boost levels of motivation resulting from employee recognition.

The company was also capitalizing on symbolic forms of recognition than other available motivation strategies such as remuneration, promotion, work appraisals, and awards. By Balancing among motivation strategies, the company could gain more than focusing more on public acknowledgement. Further studies in this area should focus on why the company preferred public acknowledgement over the other strategies of motivation and whether use of each of the strategies would lead to different motivation outcomes comparatively.

There are several studies which indicate that working conditions have an influence on job motivation for example: environmental pressure at work place [10]; lack of control over job assignment [11]; and the protection of the employee from unfair work practices or dismissal [24]. Studies also show that employees tend to prefer a job that gives them opportunities to use their skills and abilities and offer a variety of tasks, freedom, and feedback on how well they performed [19].

The findings of this study indicate that $50.57 \%$ of staff rated work home balance as either very poor or poor. This was a little above average. Of those who rated work home balance as good or very good, $69.39 \%$ felt motivated to work. The analysis however revealed that there was no significant association between protection and motivation. On the other hand, most of the employees in the study who rated the compensation and rewards as very poor were also motivated to a low or very low extent. These findings show that there is a positive association between compensation and motivation. This shows that improved work home balance was associated with motivation at work. This study shows that to improve working conditions in order to boost employee motivation as well as work performance in the long run would be a good incentive for the company productivity and performance strategy.

Previous studies indicate that training and personal development contributes to employee motivation because of the following reasons: (1) training enable employees to acquire knowledge and skills that they did not have before; hence making them better and equipping them to handle some of the previous challenges at work place which they found difficult to handle [20]; (2) trained employees perform duties confidently according to [21]; (3) a staff motivated by among other things training provides better results [23]; (4) a part from organizational goals, 
employees have at personal level what they want to achieve in or by working in the organization. When they are trained and as a result of that training accomplish their personal goals while at the organization; they feel accomplished hence motivated [25].

The findings of this study show that $50.57 \%$ of the employees surveyed reported that they had never been trained. Of those who had received training, $60.77 \%$ reported to have been trained twice while $33.85 \%$ reported to have been trained three times. This shows that generally, the company had invested much less in training and personal development. Of those trained $40 \%$ women rated the training as relevant compared to $29.93 \%$ felt the trainings were not relevant. This was also below average. $71.01 \%$ of employees who said that academic qualifications had a bearing on how they were rewarded were motivated to a high or very high extent. On the other hand $61.6 \%$ of employees who said that academic qualifications had no bearing on how they were rewarded were motivated to a low or very low extent. Most of the employees who rated the promotions in the organization as very fair or fair felt motivated to work and go an extra mile in their work. The results provide incentive for the company to invest more in training and personal development given that this is an area of management with potential that has not been utilized in order to maximize the benefits of the organization as well as build the human resource of the organization.

The findings of this study show that there was no significant association between the adequacy of the forums available to the supervisors to communicate and motivation. It findings also indicate that there was a significant association between the friendliness with which the supervisors picked and responded to the communications of employees and the motivation of those employees. The finding implies that improvements on the nature and practices of supervision can contribute to improving employee motivation and organizational performance.

The study recommends that since employee motivation remains an understudied issue among Kenyan companies; further studies should be conducted with respondents sampled from different industries in order to further understanding particularly how motivation strategies resonate with various organizational cultures in the Kenyan context. Further studies should also include quasi experimental studies in order to advance theoretical understanding of the effect of motivational strategies on employees in Kenya's organizational cultures.

\section{References}

[1] Adegbuyi, O., Oke, A.O., Worlu, R.E. and Ajagbe, A.M. (2015) Archival Review of the Influence of Organizational Strategy on Organizational Performance. https://www.researchgate.net/publication

[2] Asim, M. (2013) 3153 Impact of Motivation on Employee Performance with Effect of Training: Specific to Education Sector of Pakistan. International Journal of Scientific and Research Publications, 3, 2250-3153.

[3] Masese, W. (2014) Bottlers Kick off Restructuring to Turn around Fortunes. http://www.standardmedia.co.ke/procurement/article/2000110942/bottlers-kick-off-restructuring-to-turn-around-fortun es?pageNo=1

[4] Amabile, T.M. (1993) Motivational Synergy: Toward New Conceptualizations of Intrinsic and Extrinsic Motivation in the Workplace. Human Resource Management Review, 3, 185-201.

[5] Yang, H., Miao, D.M., Zhu, X., Sun, Y.F., Liu, X.F. and Wu, S.J. (2008) Influence of Pay Increment on Job Motivation of Chine Seamy. Social Behavior and Personality, an International Journal, 36, 1333-1340.

[6] Gupta, S.C. (2007). Fundamentals of Statistics. 6th Edition, Sultan Chand \&Sons, New Delhi.

[7] Herzberg, F.I. (1966) Work and the Nature of Man. World Pub., Cleveland.

[8] Newman, K., Maylor, U. and Chansarkar, B. (2002) The Nurse Satisfaction, Service Quality and Nurse Retention Chain: Implications for Management of Recruitment and Retention. Journal of Management in Medicine, 16, 271-291. http://dx.doi.org/10.1108/02689230210445095

[9] Savery, L.K. (1987) Effect of Motivators on Job Satisfaction. Journal of Managerial Psychology, 2, 28-31. http://dx.doi.org/10.1108/eb004422

[10] Willis-Shattuck, M., Bidwell, P., Thomas, S., Wyness, L., Blaauw, D. and Ditlopo, P. (2008) Motivation and Retention of Health Workers in Developing Countries: A Systematic Review. BMC Health Services Research, 8, 247. http://dx.doi.org/10.1186/1472-6963-8-247

[11] Wright, B.E., Moynihan, D.P. and Pandey, S.K. (2012) Pulling the Levers: Transformational Leadership, Public Service Motivation, and Mission Valence. Public Administration Review, 72, 206-215. http://dx.doi.org/10.1111/j.1540-6210.2011.02496.x

[12] Cao, H., Jiang, J., Oh, L.B., Li, H., Liao, X. and Chen, Z. (2013) A Maslow’s Hierarchy of Needs Analysis of Social 
Networking Services Continuance. Journal of Service Management, 24, 170-190. http://dx.doi.org/10.1108/09564231311323953

[13] Chuang, N.K. (2009) Hotel Expatriates’ Motivations to Work Overseas and Their Competences for Success. Paper Presented at the 2009 International Council on Hotel, Restaurant, and Institutional Education Annual Conference (CHRIE), San Francisco, 29 July-1 August 2009.

[14] McNeese, G. (1997) Factors Contributing to Nurses Demotivation with Recognition Initiatives: A Review of the Research Literature. International Journal of Nursing Studies, 44, 297-314.

[15] Pedalino, E. and Gamboa, B. (1974) Behaviour Modification and Absenteeism. Journal of Applied Psychology, 59, 694-698. http://dx.doi.org/10.1037/h0037505

[16] Springer, G.J. (2011) A Study of Job Motivation, Motivation, and Performance among Bank Employees. Journal of Global Business Issues, 5, 29-42.

[17] Okumbe, J.A. (2001) Human Resources Management. Education Development \& Research Bureau, Nairobi.

[18] Nzuve, S.N. (2007) Management of Human Resources. Basic Modern Management Consultants, Nairobi.

[19] James, O. and Lucky, O. (2015) The Impact of Training on Employees Job Erformance: An Empirical Study of Selected Organizations in Warri, Delta State. Journal of Policy and Development Studies, 9, 111-125. http://dx.doi.org/10.12816/0011170

[20] Purcell, J., Kinnie, N., Hutchinson S., Rayton, B. and Swart, J. (2009) People Management and Performance. Routledge, London and New York.

[21] Chapman, A. (2003) Maslow’s Hierarchy of Needs. http://www.businessballs.com/maslow.htm

[22] Willis-Shattuck, M., Bidwell, P., Thomas, S., Wyness, L., Blaauw, D. and Ditlopo, P. (2008) Motivation and Retention of Health Workers in Developing Countries: A Systematic Review. BMC Health Services Research, 8, 247. http://dx.doi.org/10.1186/1472-6963-8-247

[23] Mugenda, A.G. (2008) Social Science Research: Theory and Principles. Acts Press, Nairobi.

[24] Orodho, A.J. (2003) Essentials of Educational and Social Science Research Methods. Mazola Publishers, Nairobi.

[25] Koontz, H. and Weihrich, H. (2010) Essentials of Management: An International Perspective. McGraw Hill, New Delhi. 